\title{
A Study of Interdisciplinary Dialog of Music and Dance in the 21st Century Turkey through Performed Examples
}

\author{
Ayca Daştan, Ayrin Ersöz
}

\begin{abstract}
It is possible to simplify the essential components used in the creative production of contemporary dance as time, space, and body. In this context, it is known that the component of time is directly associated with the art of music. Since the beginning of historical evolution and organic association of dance with music, it has become especially problematic as of the second half of the 20th century. It is known that in the 20th century, artistic disciplines determined their boundaries with artistic essentialism; and within those boundaries, they built their aesthetic forms as self-constructing elements. This essentialist distinction made it possible for every discipline to determine their components in an abstract fashion, and thus search for commonalities among the founding principles of each discipline in interdisciplinary relations. These commonalities enabled interdisciplinary dialog and a non-hierarchical, horizontal structuring of artworks. Each work of art thus created existed in the visibility of its own discipline's boundaries. In this article, the interdisciplinary dialog is involved in the creation and performance of dance and music. The article focuses on the transformations during the interdisciplinary dialog of dance and music, which merge in a historically ontological foundation, and which are created outside their traditional orientation.
\end{abstract}

As the structural transformations that interconnect the here-and-now experience of dance and music in a shared space are studied, the focus is on the 'synchronicity' method of interdisciplinary modes of production in dance and music. In order to study the synchronous production of dance and music through examples, Atrophy 1 House of Names, Antigone Divided, and Sar have been chosen. They were produced in Turkey after the 2000s. In this context, how the interdisciplinary and synchronous production mode of dance and music is associated with improvisation will be presented through a choreographic analysis of the works as well as the semi-defined interviews with the artists.

Keywords:- contemporary dance, music, discipline, interdisciplinary, interdisciplinary dialog, choreographic analysis, Atrophy 1 House of Names, Antigone Divided, Sar, Turkey.

\section{INTRODUCTION}

Interdisciplinarity presumes a knowledge domain to collaborate with other domains. When this is applied to arts, especially music, it entails artists from different disciplines coming together to form a task force and change and improve the approaches of their disciplines to be able to deal with, solve, and adapt a specific problem. Therefore, interdisciplinary studies, where music collaborates with dance in order to reach common desirable goals, allow not only innovations and alterations in terms of choreographic practices, composition techniques, and movement analyses, but also opportunities to deepen understanding into other knowledge domains such as aesthetics and philosophy. In order to realize these goals, musicians collaborate with choreographers, other artists, and researchers following the requirement of the artistic production process. As a result of discussions and exchange of ideas, and experiences between different disciplines and domains of knowledge, it becomes possible to enrich their knowledge. So, better and more useful tools can be obtained in continuing joint projects and artistic collaboration for participant disciplines and knowledge domains. Here, what matters is not how the interdisciplinary studies are categorized, but the qualities of the problems these studies deal with as well as the solutions they come up with for those problems, and the artworks they produce as a result of the artistic creation process.

Contrary to the commonly accepted approaches in music and dance, it is possible to say certain concepts that emerge during the production of works in interdisciplinary dialog have a transformative power for both artistic fields. It is observed that music that emerges during the production of dance has a direct, fundamental, and essential impact on bringing out the nature of the dance. Similarly, it is imperative that while musicians work with dancers, they experience the movement visually at that moment so that they understand sounds become visible. Meeting at a common point of experience, appreciating the successful past collaborations, and understanding the common vocabulary of both disciplines are significant components in the growth of every artist. Grasping the artistic and creative approach of artists will help provide a successful collaboration. Participants of joint projects should be aware of several circumstances and adjust to different situations. 
Interdisciplinary dialogs can manifest themselves in several different ways. First of all, the attitude towards collaboration can be discerned through whether the components of the collaboration were produced at the same time or separately; and whether they were independently designed or not. A composer and choreographer both develop their own methods to reach a balance in a collaborative project. They need to share and respect each other's ideas. Collaborating artists improve their creativity by sharing and learning from one another.

This study looks into the relationship between composers and choreographers based on collaboration. Insight can be gained by tracking the history of different collaboration processes between modern music and dance. In the light of the works Atrophy 1 House of Names, Antigone Divided, and Sar, this study also deals with the balance of creativity between composition and choreography and looks into different collaboration processes used for contemporary projects. Firstly, this study is essential, especially for composers and musicians at the beginning of their careers, who want to collaborate with choreographers. Composers and choreographers, as well as musicians and dancers, can understand one another's composition process and communicate more effectively by defining and comparing a common lexicon for music and dance.

This study has three sections: The first section contains a historical overview of collaborative projects. The second section is about how the interdisciplinary approach to arts and performance arts should be conceptualized. The last section includes three works: Atrophy 1 House of Names, choreographed by Ayrin Ersöz; Sar, a collaborative effort by Mihran Tomasyan - Saro Usta; and Antigone Divided, a collaboration by Ayrin Ersöz - Ayca Daştan.

\section{> A Short Historical Background of the Relationship between Dance and Music in Western Performance Arts \\ Western dance is one of the most conducive examples in examining the relationship between music and dance. The concept of dance in this article is limited to western dance forms like ballet, modern dance, and contemporary dance.}

When we look at the history of western dance, for the most part, it is based on the harmonious union of dance and music. Music depends on the same rhythmic, aesthetic, and atmospheric structure as the dancers dancing to that tune at the same time.

Dance started to be accepted as an art form in the West with the Renaissance. In Renaissance Europe, where dance was problematized as an art form, it can be seen that the connection of dance to music is closely related to the process of choreography (Ersöz, 2011). In the dance tracts written in that period, certain expressions can be observed as to the need for dance to be directly thought of together with musical concepts in order to elevate it to the status of liberal arts. Choreomusicologist Inger Damsholt, in his work titled Choreomusical Discourse, the Relationship
Between Dance and Music, states that in the rhetoric of dance from the mid15th century to the mid18th century, there was a certain level of homogeneity. Therefore, in that period, it is possible to define some general conditions about the relationship of dance and music (Damsholt, 1999, 11).

From the mid15th century to the mid 18th century, we can see the concept of time as the basis of the relationship between dance and music. It can be stated that dance and music are a temporal phenomenon together and share synchronicity. During the Renaissance and the classic period, it can be seen that concepts of being in time with music (synchronicity) and accordance (harmony) are essential in the relationship between dance and music (Damsholt, 1999, 41). Damsholt claimed that, in that period, the synchronicity of music and dance did not refer to dance steps visualizing the rhythmic structure of music, but that it meant the dancer listening to the music and adapting the dance to the temporal process created by the music (ibid, 41). However, dance is elevated to art status by not absolute structural and aesthetic submission to the music, but by sharing the same temporality with the music.

The works of art produced in the Romantic period, from the 18th century to the late 19th century, define the aesthetic taste. In that period, we can see that music is elevated to the highest point in the Hegelian hierarchy of art. Music almost points to the existence of the spirit in the physical realm. In this period, dance or ballet was transformed from a social functionality into an autonomous art form. This art form, performed entirely by professionals, was staged in theaters where a sharp distinction was observed between the spectators and the dancers. During the Renaissance and Baroque periods, the harmonious relationship of dance and music disappeared, and ballet became entirely dominated by music. In this period, eminent composers started to compose ballet music, and music became the main component of ballet choreography.

Additionally, following the emerging aesthetic, ethic, and cultural values of the bourgeoisie, works of ballet were composed around individual narratives. The narratives both followed the Christian morality and mythological tales and legends. The Romantic period had ballet impresarios like Sergei Diaghilev making a profound impact and turning ballet into an art form with the emergence of troupes like Ballets Russes. Also, it was a period when important choreographers like Marius Petipa, whose works are still staged, lived. At the same time, this period allowed such masterful composers as Pyotr Ilyich Tchaikovsky and Igor Stravinsky to be known with their works of ballet. In this period, it is possible to say that ballet music became independent of dance in concert halls while dance became utterly dependent on the music composed specifically for it. In the Romantic period, there was an absolute harmony between the music composed for each ballet work and the choreography using a specific language of dance (danse d'ecole). 
George Balanchine, a choreographer of Russian origin, brought a new approach to the dance creation by adopting choreography as a domain of mastery. He approached the physical and professional levels of dancers as objective data. He uprooted the entire relationship of music and ballet by treating the creative process as a fine craft and treating the creative components of choreography in terms of their objectivity. Balanchine's dance is not a simple imitation or representation of music through movement, but as Edwin Denby pointed out, Balanchine's dance does much more than following the music to the letter. Instead, the two disciplines sort of put pressure on each other (Butkas, 2007, 225).

It is seen that the process that started with Balanchine continued with the emergence of modern dance. Modern dance emerged in the West as individualism encompassed all areas of life; and women took active roles in urban life with the influence of individualism, and sought new ways with which to express themselves. Rudolf Laban, one of the theoreticians of expressionist dance that emerged in Germany, is known for developing the notation system in modern dance. Thanks to his works, dance movements got emancipated from dependency on musical structures. Because of his movement analysis, the principles necessary for the creation of dance movements and their compositional design were designated. Those primary principles are body, space, time, and energy.

The visibility of American women in the public sphere and on the stage to express themselves through their bodies was simultaneous with Emile Jacques-Dalcroze's teachings becoming widespread in America. Dalcroze believed that he could build an expressionist structure, apart from words and sounds, based solely on body movements and postures. So, he developed a system with this belief. Jacques-Dalcroze worked on music-related simple movements such as energy, body weight, and walking, sliding, running, hopping, and jumping. This way, Dalcroze demonstrated that movements could appear in different forms instead of pre-taught steps.

However, in this process, a system of principles became necessary to associate with movement creation. These principles made it possible to define and scaffold the source of the movement in the light of certain concepts. Body movement was placed in the ontological essence of dance and was analyzed by being simplified to some components for the first time.

In the known physical world, movement has three basic components: space, time, and energy. Every moving object takes up space, moves in time, and spends energy. The significance of these physics concepts for dance is that dancers use up a certain amount and quality of energy, in a certain time frame; and they create a reciprocal and complicated reference system between their own body parts and with each other's bodies in the relatively constant performance space. They also form their movements in a choreographic process (Ersöz, 2005, 14).
The fact that movement was defined as the ontological essence of dance changed its relationship to music as well. Movement is designed in space and time; and music is not seen as the necessary condition for the existence of dance (Ersöz, 2005, 62). What connects both disciplines is the compositional structure of music. The belief that dance cannot be an art form without composition was clearly stated in both Horst's work and also in Doris Humphrey's book The Art of Making Dances (1959). She is one of the pioneer choreographers of modern dance. In both of these works, composition concepts are equal to musical concepts, and function similarly. Again, in both works, it is emphasized that an oeuvre with a particular compositional order would give dance its aesthetic value. Horst explains it thus: "As this order constructs a tonal structure, in dance, it builds a visual structure" (Horst, 1987, 23).

\section{> Contemporary Suggestions in Music and Dance}

Sally Banes, a dance theoretician and historian, has a very controversial post-modern dance conceptualization. Choreographer Merce Cunningham introduced postmodern dance works in the 1960s. He collaborated with the composer John Cage. These enabled new conceptualizations in the interdisciplinary collaboration of dance and music. The most salient suggestion of the duo for the history of dance and music is the use of randomness in the collaboration of both disciplines and the design of their own compositions. There are probability and randomness concepts perceived as a radical break from associating dance and music in the innovative composition approaches, especially in the artistic collaboration of Merce Cunningham and John Cage, which emerged as a result of John Cage's musical suggestions.

In those years, a new movement by the name of Judson Dance Theater came out in the US. Composer Robert Ellies Dunn taught dance composition and improvisation in Merce Cunnigham's dance studio in the early '60s. He did these workshops upon John Cage's invitation and adapted contemporary concepts controversial in music to dance. Most importantly, he made suggestions about improvisation concepts. The analytical structures Dunn used in his classes allowed the participants to produce their work based on improvisation instead of given formulas (Carter, 2000, 185).

In Judson Theater, there were no classes geared towards a specific dance language or technique. Instead, workshops were organized on searching for new ideas in dance. This movement was not an institution in the traditional sense. It formed the basis of a democratic arena where artists from different disciplines like visual arts, music, and dance freely came together and worked in collaboration. Many theoreticians state that the almost organic connection between dance and music forged historically got gradually severed with the 20th century, and that dance became an independent art form (Damsholt, 2006, 4). Mason claims that the fact that dance developed as an independent art form and sought its research topics made it possible for dancers, musicians, and composers to create more conscious collaborations (Mason, 2012, 17). 
In western dance history, the relationship between dance and music traditionally demonstrated a linear progress from the Renaissance to the 20th century. This progress peaked in the1950's with radical enlightenment in Merce Cunningham and John Cage's collaboration. In the 1960s, with the Judson Church Movement, the relationship between dance and music dissolved. Also, the idea that the unquestionable and seemingly absolute relationship between dance and music finally ended in the mid 20th century is a dominant one (Damsholt, 1999, 5). It needs to be said that the cause of this disintegration lies with the idea that sees the only movement as the ontological essence of dance and wants to free it from all elements like the current languages of dance, music, stage, decor, costumes, and narrative.

\section{$>$ About Disciplinarity in Art}

In any discipline, when the scope of a study to be carried out in order to solve a possible problem or to enhance knowledge in that niche exceeds that of one discipline or research area, an interdisciplinary study becomes necessary. In such a case, in order to integrate all the knowledge, data, techniques, viewpoints, concepts, and theories that are derived from various related disciplines, disciplinarity comes to the fore (Barkovic, 2010, 952).

Here, it might be necessary to pay attention to especially interdisciplinary works. In Arapoğlu's words, interdisciplinarity, accepted as a step ahead of multidisciplinarity focuses on pointing out the systemic problems of 'the real world' in a certain way and pushes participants from various disciplines to transcend boundaries related to the problem at hand and create new knowledge (Taşkesen, 2016, 16).

It has been influential in redefining the field when the artists opposed visual arts to determine their boundaries with definite criteria, gathered both ready-made objects and designed objects in a specific artistic context in different spaces together with the spectators using the method of interboundary transitivity. Transcending their discipline and connecting with many other disciplines that encompass life, artists create their works by establishing a complicated relationship with objects and images that construe social meaning from different sciences. It can be seen that these works are open to a certain relationality, which is realized through both creation and presentation in terms of sharing with the spectators (Bourriaud, 2005, 6).

Relationality is an essential device in the production of works of art with an interdisciplinary approach. This device aims to bring together different artistic fields and works of art with the artist and, as a result of this connection, create a space to enable them to protect the authenticity of their discipline. The fundamental principle here is to provide a dialog on mutual ground while not allowing any discipline to lose its authenticity.
Today, however, artistic cooperation brings possibilities of solidarity along with it as well. Cooperation always points to 'not yet, but soon.' It points towards a possible future completion and is mobilized by the hope of sincere social productivity. In the case of cooperation, the hope that a particular surplus-value would emerge presupposes relative equality among the participants. Not every social opportunity selectively put in motion by cooperation is shaped by a harmonious union and a utopic community. Here, we need a different terminology now in order to define contemporary artistic cooperation. Belgian sociologist Rudi Laermans proposes to name the social potential mobilized by creative cooperation the common (Laermans, 2011). Cooperation means being part of the common and bringing the common out into the open. Therefore, Laermans suggests defining the 'here and now' state that concretizes the experience of both the social and artistic practice of today as commonality (Laermans, 2011).

\section{> Interdisciplinary Dialog Forms of Music and Dance}

The fundamental principle of interdisciplinary approach in music and dance is being completely open to cooperation. It is apparent that musicians and dancers meet at a common creative ground, and works of art taught with an interdisciplinary understanding that compels a creative process generously enrich this ground with a significant artistic contribution to both these areas. As Katherine Teck says in her book titled Ear Training for the Body, "I like to work together because what we feel and get together may be much better than what we can achieve alone" (Teck, 1994, 53).

\section{Asynchronous Modes of Production and Examples}

Together with the modern era, when disciplines are demarcated with sharp lines, and every field of art clearly defines its boundaries, it is seen that opportunities decrease for choreographers to create works with musicians. This process caused choreographers to seek ready works as recorded music is easy to reach. They even used works not composed for dance. For instance, in the Guardian newspaper dated Sept. 5, 2017, there was a review about three women choreographers who interpreted Beethoven's Grosse Fuge in Dance Umbrella festival demonstrating the relationship they established with the work. Winship discusses how American artist Lucinda Childs, Belgian Anne Teresa De Keersmaeker, and French choreographer Maguy Marin interpreted this musical piece, which is 'very hard even to play,' through dance (Winship, 2017).

Winship comments that every choreographer works closely following a musical composition, building the choreographic structure by examining the written partition, but each of the three results was utterly different (Winship, 2017). What is discussed here is that in modern dance choreography, in asynchronous productions, choreographers can feel free in the relationship they establish with a ready composition, contrary to common thought, and that they can actualize their works according to their specific interpretations. 
Synchronous Modes of Production and Examples

It has to be said that in synchronous production of music and dance, the real deal is the ability to improvise. In this article, the examined work Atrophy 1 House of Names is a good example of synchronous production process. In this work, as a result of the improvisations, discussions, and trials by the musicians that determined the text around the mainframe of the work, the final forms were decided step by step and together. In the final compositional structure of the choreography, definite moments of the dance, music, and the moments of open composition are used together. How these would come about were also decided as a result of synchronous production.

\section{$>$ Synchronous Production and Examples with the Improvisation Principle}

The term improvisation points to spontaneity and ready-made designs within the here-and-now experience. The word improvisation reminds us of certain actions, some of which are creation, invention, or resourcefulness. It refers to a movement, sound, or image in the process of birth where it can be experienced as a natural, spontaneous act. However, improvisation is possible only with a mastery of skill and knowledge.

Improvisation feeds off of the intuitive part of the human mind, and expresses itself as creative acts. Improvisation in art makes it possible to suspend the given construct structures and allow non-traditional components to emerge. Improvisation is a pre-requisite for the spontaneous creation of new forms. Improvisation is a method frequently used in the choreographic forming processes. Additionally, it constitutes an integral part of the creative process. Improvisation is in cooperation and part of the synchronous production process with dance and music, where it points to a union at the moment of representation in which the audience is present.

\section{$>$ Production and Examples with the Randomness Principle}

The randomness method, identified with the American composer John Cage and American choreographer Merce Cunningham's works, is a defining suggestion for performance arts in the example of interdisciplinary dance and music.

Cunningham abandoned the idea that the dance needs to tell a story, be based on music or express an emotion, so he achieved a radical break from both the classical ballet and the second generation of modern dance. As dance is no longer a means of telling a narrative and expressions, his dance focuses on the physical reality of the body instead of psychological aspects such as human feelings or instincts. So, the fundamental problem of dance cannot be anything other than the dance itself. Cunningham's dance performances do not refer to anything other than themselves (Ersöz, 2005, 104).
Besides, Cunningham abandoned melodic designations in the relationship of music with dance in his works. He deals with music as an independent art form in the production of dance and makes sure its specific identity is audible and visible. Any harmony between dance and music is only accidental and falls outside the purview of choreographic purpose.

\section{> A Study of Atrophy 1 House of Names, Sar and Antigone Divided in terms of Interdisciplinary Dialog of Music and Dance}

In this next section of the article, the interdisciplinary relationship between dance and music in the context of three works produced in the contemporary dance scene in Turkey in the $21^{\text {st }}$ century will be examined. After the disintegration of the Ottoman Empire, the Republic of Turkey was established in 1923. The Republic aimed to reach the cultural, political, and economic levels of development of western civilizations, and applied a series of reforms in all aspects of life. In art, there were also definite westernization efforts. In 1948, ballet tried to settle in firstly through schools and then with troupes. In the 1980s, modern dance first got into state opera and ballet ensemble with training and choreographies. Then, it became a department in the conservatory. So, western dance had a presence in Turkey. Below, modern dancers who graduated from two established dance academies in İstanbul, and the interdisciplinary dialog of dance and music in the light of Ayrin Ersöz and Mihran Tomasyan's works are investigated. In both their works, interdisciplinarity is seen to be the primary approach.

\section{Atrophy 1 House of Names}

This work started with a provocative invitation by the choreographer Ayrin Ersöz in 2007 to make a collaborative production of dance, music, and visual design. Ayrin Ersöz wrote the text and did the choreography, and the work was created with the interdisciplinary effort of three musicians and visual designers.

The text of the project became the map and plan of the performance at the end of the process. All the disciplines collaborating in the piece were included in the design through the map created by the text. In this work, because the focus is on the music and dance, the visual design in the project was deliberately not detailed. The aim of all the participating disciplines in Atrophy 1 House of Names was the same. That is, it aimed to solve a common problem.

With the first rehearsals, negotiations were carried out to come up with a joint plan in which a method could be found to ensure that every participant could share the desired performative result. As a result of the exchange of ideas about the function of all the components in the work as well as the exposition of structural differences, an inquisitive approach was enabled with the questions brought on by other disciplines as to resolve issues of how the production and each discipline should proceed with their own methods. 
Music, dance, and visual design equally played a part in the production of the work based on the synchronous production principle. There was a very close interaction between dance and music. The text of the work constituted the backbone of the production and was inspired by writers like Milan Kundera, Tomris Uyar, Italo Calvino, and Eduardo Galeano, and texts like the Torah. It served as a bearing in the production of dance and music. An interdisciplinary dialog came out of the reciprocal interaction of dance and the compositional designation of music.

All the disciplines sharing the same space and time made themselves visible in the narrative flow of the choreography. Improvisation was also used as an observation tool. It made it possible for the musicians to observe the movements or inertia of the dancers while the dancers also focused on the sounds, resonance, moments of silence, and rhythm produced by the musicians to direct their observations to them.

In Zeynep Günsür's words, the interdisciplinary structure of the work is:

This is truly a performance that does justice to the interdisciplinary approach. Generally, one of the traps interdisciplinary works fall into is different disciplines coexisting on stage with no transmittance and without actually affecting each other. On the other hand, House of Names managed to build a structure where music, visuality, dance, text, and body are intertwined inseparably, carry and transform each other (Günsür, 2009, 80).

The work contains a special production, where not just dance and music, but also photography and interactive media design, inspired by visual arts, are blended.

\section{ANTIGONE DIVIDED}

Sophocles' play Antigone was staged in many ways; and it inspired many works of fiction as well. Ayrin Ersöz's version is still a work in progress in partnership with different dancers and musicians. The text of the tragedy will make important statements about the contemporary dance and music scene in Turkey by discussing its transformation to our times and desires of interpretation, also in terms of the nature of the work as well as the harmony among the performers and its statements about the creation process. It is performed with a method necessary for the improvisation principle in performance arts. Different artists working together try to get Antigone to be interpreted and transformed by every artist in his/her own way.

Antigone is the third play by Sophocles in his Oedipus Rex tragedy trilogy. In many sources, it is said that Antigone is based on a pre-Hellenic legend.

The creation and performance of this work enabled the birth of original ideas and their expressions in dance and music. Also, it led to a connection between different disciplines which were included in the performance. People in different disciplines could contact each other aesthetically in Antigone's mythical character and destiny. They perceived both Antigone and indirectly their own experience. This perception opened space for them to react, come together, and share in their own artistic field. It aims to allow performers to share their experiences, exchange ideas, and engage in dialog with the performers as well as the audience. This performance is an ideal example of synchronous production as the improvisation method was employed in all its stages.

It is performed with the free improvisation principle. The participant disciplines are open to knowing and understanding each other during this process of improvisations. During rehearsals, it searches for expressions of dance and music. It uses different means for this purpose. For music, this is related to resonance, while for dance, it stems from the body and movement. However, time and space are the two most comprehensive and definite components of the work. Music and dance experience the volume, movement, and spatial presencein resonance and bodily movement - together with shared space and time.

It is necessary to stress how the improvisation process works in order to understand different versions of Antigone Divided. During the performance, improvisations were timed out, and without any compositional expectation, it aimed to create dance and music synchronously in shared space and time around a common theme, nurturing each other.

Performers are encouraged to create from out of the moment, and what is available. These come out of the experiences of the musicians and dancers, as well as what is perceived during the temporal and spatial sharing with the other discipline. We can call this process nurture from within. This inner nurture includes what the performers already know and what materials they encounter at the moment with an exploratory feeling.

Two versions of Antigone Divided were performed until the first semi-formal show. The first one was Antigone Divided: Lifeless; and the second one was Antigone Divided: Fire. Antigone Divided: Lifeless was performed by the dancer Leyla Postalcioğlu and pianist Ayca Daştan. The second one, Antigone Divided: Fire was performed by the dancer Gizem Aksu and pianist Ayca Daştan, cellist Hasan Yoksulabakan and classic kemancha virtuoso Aslıhan Eruzun Özel.

For each Antigone Divided performance, choreographer Ayrin Ersöz presents themes that would direct, provoke, and distinguish the production in the improvisation meetings. Here, the objective is to keep the search for novelty ever alive, and prevent the performers from resorting to their familiar routines. These themes are not announced to the performers beforehand. So, they are unprepared for them. Here, it is aimed to make the performers focus. Momentary awareness of the body and sounds keeps the acts of listening and watching alive and 
alert. Not every meeting that ends points to a real end. Instead, it leads one to think about the performance. Making sense, questioning, and searching continue in the minds of the performers.

In Antigone Divided, the audience witnesses multiimprovisation techniques, which also involve the dancers and the musicians. The orders cause a mental reflection in the mind of the audience, and right after that, they follow how these orders are interpreted and improved by the dancers and musicians in terms of movement and resonance. Open form, above all, eliminates the hierarchical positioning among the artists. There is no difference here between the creators and performers. The performer is also the creator, which allows sharing the responsibility of the work as well.

During the practice, each participant also determined how the interdisciplinary dialog should work per their understanding of art and their approach to the work. In this process, together with the approach of the performers, their synergy also affected the work and the improvisation performance of each artist entirely.

The sense of trust between the performers during improvisation is vital. Without trust, there cannot be surrender. Surrender means allowing the individual to emerge and allowing the others to participate with their individuality amidst all this cycle.

Participants provoke and support each other during improvisation, pushing the boundaries in the disciplines all the time. They look for silence and immobility and destroy each other's states. All these are experienced from time to time during improvisation. There are many situations encountered during improvisations that evoke many different pleasant or unpleasant emotions; or wanted or unwanted movements and sounds; easy or hard contacts that paralyze the participants completely; and that create resistance.

What needs to be remembered here is that the participating artists should be aware that those moments when they feel the most pressured, or even ready to give up the improvisation are the ones that will spark them to an original bodily and mental creation because they push their own limits and those of their disciplines at those moments. Free improvisation rehearsals of Antigone continued uninterrupted, albeit exhaustingly, leading to original innovations. The post-rehearsal experiences and emotions were shared, and discussions were held about how new ideas came about following resistance points, and how those ideas could shape the improvisation process, which was all equally shared in responsibility. These assessments were made in order to sustain the improvisation partnership, collaboration, and dialog as well as a reminder of the common starting point and to keep alive the artistic as well as the ethical conceptualization of this mode of working, and not to discuss or analyze the forms of dance and music to be used in the next improvisation session.
These discussions kept the practice going and encouraged the inner motivation of the performers.

$>$ Sar

Sar is a joint product of the choreographer Mihran Tomasyan and musician Saro Usta. These two artists were childhood friends; and they said that they started their music careers just by listening to music for a long time. This is their first joint project. It is said that one of the components of Tomasyan's artistic identity consists of creating works in the daily comfort of their lives through long conversation and music listening sessions at the end of which their production is shaped. Another vital element of Mihran Tomasyan's artistic language is the use of objects in his choreographies. Objects are represented in a choreographic context in layers of social traumas (Ersöz, 2019). Tomasyan says that as he starts working, first of all, he deals with the object and focuses on the "thingness" of the object (Tomasyan, 2019). At the end of the thingness processes of objects, the transformation of the object allows the choreography to move on. The object neither is just a thing nor represents anything in his works. The object transcends its functionality and becomes a key that opens different layers of meaning (Ersöz, 2019).

Tomasyan's relationship with music is based on layers of meaning. In his works, music is a reminder of social traumas. He uses forgotten Turkish and Armenian songs one after the other in his works. Traces of a painful past can be heard from the stage.

This work starts with Tomasyan writing on a white piece of paper covering the stage "this is a mountain story." This is a direct reference to the Mount Ararat, which gives us a clear clue about the work. With the synchronous pieces Saro Usta plays, the audience is invited to a specific atmosphere. Saro Usta and Mihran Tomasyan's collaboration, dating back many years, sharing a childhood and destiny, means a lot for the feeling of the piece. Shared stories, troubles and traumas make up this piece of work.

The work is the same in its construct, but in each performance, there are partial improvisation sections that allow change. In these improvisation sections, Saro Usta and Tomasyan make a difference in timing, breath, and dynamics on stage that day according to the mode of the moment and the common feeling they establish with the audience. It is observed that in this work, music and dance take shape depending on each other, and the audience is included in the common feeling. The artists open the space to dialog with the audience after each performance. It can be understood that dialog is a crucial component of the work since it functions as an open work from the production to the performance stage.

Saro Usta: We worked with Mihran in the thought stage. Here, Mihran does his own thing, and I do mine. In that sense, we can talk about a division of labor but during the design stage, we thought of everything from "where to put what sound' to "what kind of material should we use 
here?" So, other than the dance and music distribution on stage, I don't see any distinction (Esen, 2016).

Saro Usta said the above words in an interview with Tuğba Esen on Feb. 13, 2016, for Agos to state that the creative process lies within the cooperation of two artists in a complicated way. In the same interview, Tomasyan established his view that during improvisations, a paper turning into a bird and the work becoming a constant image, while materials transform the piece as the process continued (Esen, 2016).

\section{CONCLUSION}

In the 21 st century, we see that contemporary dance and music gradually drift away from a holistic art approach and criticize the teleological art experience. They do not have any claims to tell grand narratives. They create brand new contexts, not to expose the audience to illusions or favor works that prioritize experience. With the artistic revolutionary movement, artists destroy the notion that artists distance themselves from the social and are pioneering subjects in a hierarchical context. In dance and music, approaches towards the humane, collaboration, and opening different fields of experience where art is itself the subject of a work as well as a craft are preferred.

In the three works studied in this article, it is manifested in different forms that letting go of oneself in space and time is an essential element of interdisciplinary dialog between dance and music. Both the musicians and dancers listen to the other within the creation and have the skill to transform this at the moment they are in.

Atrophy 1 House of Names is an important example of interdisciplinary efforts in terms of synchronous production with semi-improvised, semi-constructed pieces drawn out in long rehearsal processes. In this work, we see that disciplines meet at a common ground without losing their authenticity. Similarly, Sar is a production where musicians and dancers coexist in terms of musicality, spatiality, and movement. It is an example of synchronous productions where dialog openly reveals itself. Sar allows different layers of meaning to open up on stage. Here, we should not overlook the fact that music and moving material were synchronously produced with the stories and memories about the lives and identities of the artists, forming an invisible layer.

Antigone Divided is perhaps the most direct example of an interdisciplinary dialog of dance and music because it opens many possibilities and layers for spatial and temporal dialog while spatial and temporal restrictions continue. Here, dance and music are organically intertwined, forcing each other into existence. They are responsible for each other's existence, and their cooperation ensures the other's visibility and presence. The performance of the piece requires a constant state of vigilance, a here-and-now experience with absolute presence and openness in terms of continuity of dialog in the reciprocal responsibility of both the dancer and the musician. This work makes new suggestions for performers in both fields of art to confront their own field and deal with the problems causing the blockages there today.

This article has been written in order to contribute to academic work in performance arts by examining works that try to build open constructs in the suggested forms and performances. They are inspired by conceptualizations within the universal art discussions, excluding those about identity in the contemporary Turkish context concerning the collaboration of dance and music.

This study questions whether it is possible to have a non-hierarchical, horizontal production and performance form in the disciplines or make new suggestions in the performance, approach, or even training of both dance and music in an interdisciplinary fashion, and offer a more democratic and open dialog to the audience.

It seems possible in the light of the works studied here. The artists involved in these works, especially those in Antigone Divided and Atrophy 1 House of Names, are also academicians. This is important in terms of trying to apply the concepts they used in their works in education. There are significant lessons to be learnt for the historical transformation of both disciplines from the space created by the interdisciplinary dialog of dance and music.

\section{REFERENCES}

[1]. Barkovic, D. (2010). Challenges Of Interdisciplinary Research. Interdisciplinary Management Research. Vol. 6, pp. 951-960.

[2]. Bourriaud, N. (2005). İlişkisel Estetik. Trans. Saadet Özen. İstanbul: Bağlam Yayıncılık.

[3]. Butkas, M. (2007). George Balanchine. ed. Marion Kant. Cambridge: The Cambridge University Press.

[4]. Carter, C. L. (2000). Improvisation in Dance. Journal of Aesthetics and Art Criticism. No.58(2), pp.181182.

[5]. Damsholt, I. (1999). Choreomusical Discourse: The relationship between dance and music. Copenhagen: University of Copenhagen.

[6]. Damsholt, I. (2006). Mark Morris, Mickey Mouse, and Choreomusical Polemic. The Opera Quarterly. Vol.22, No.1, pp. 4-21.

[7]. Ersöz, A. (2005). Çağdaş Dans Sanatında Koreografi Sürecinin Üretici Unsurlarına ve Yaratıcı Yönüne Kavramsal Yaklaşım (The Conceptual Approach to Productive and Creative Elements of Contemporary Dance Art), Unpublished Master Thesis, Yildiz Technical University, Social Science Institute, Istanbul.

[8]. Ersöz, A. (2011). Rönesanstan Günümüze Dansın Sorunsallaştırılması, (Problematization of Dance from Renaissance to Present), Unpublished PhD Dissertation. Istanbul University, Social Science Institute, Istanbul.

[9]. Günsur, Z. (February 2008). Milliyet Sanat. Vol.587, pp.80-81. 
[10]. Horst, L. (1987). Modern Dance Forms in Relation to Other Arts. Princeton, N.J.: Princeton Book Co.

[11]. Laermans, R. (23 Feb 2011). Artistic collaboration and the promises of communalism.A lecture by Rudi Laermans at Tanzquartier. Vienna.

[12]. Mason, P.H. (23 Feb 2012). Music, dance and the total art work: Choreomusicology in the theory and practice. Research in Dance Education. Vol.13, No.1, pp.5-24.

[13]. Taşkesen, O. (2016). Yerelden Evrensele Sanatta Disiplinlerarası Bir Yaklaşım Uygulaması. AtatürkÜniversitesiGüzelSanatlarFakültesiDergisi. c2, pp.15- 27.

[14]. Teck, K. (1994). Ear Training for the Body: A Dancer's Guide to Music. Princeton Book Company.

[15]. Ersöz, A. (2019) Interview with Mihran Tomasyan. Unpublished. Istanbul.

[16]. Ersöz, A. [11.04.2019]. https://ayrinersoz.com/ .

[17]. Esen, T. (2016). Bir dağ keşke sadece bir dağ olsa. Agos Newspaper. http://www.agos.com.tr/tr/yazi/14355/bir-dag-keskesadece-bir-dag-olsa.

[18]. Winship, L. (2007). Leap over Beethoven: how his fiendish fugue inspired three dances, The Guardian. https://www.theguardian.com/stage/2017/sep/05/troisgrandes-fugues-lucinda-childs- anne-teresa-dekeersmaeker-and-maguy-marin-beethoven 